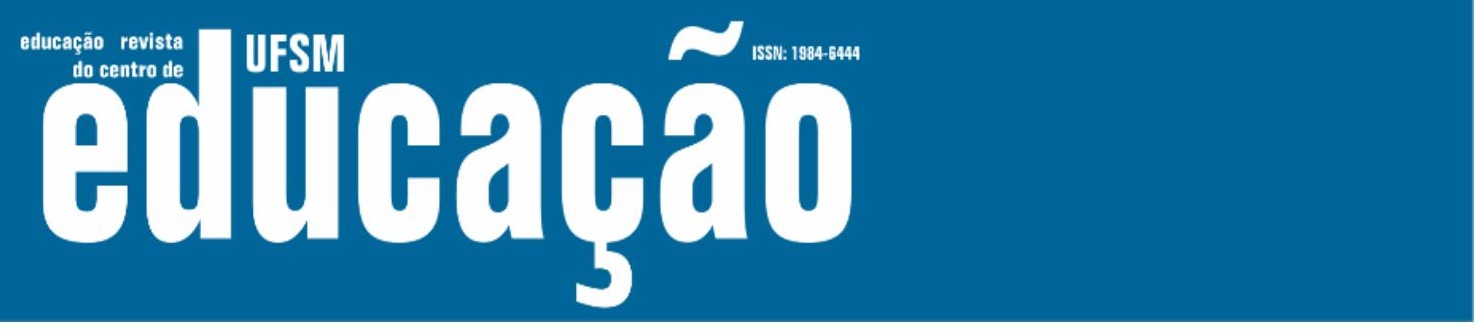

ISSN: 1984-6444 | http://dx.doi.org/10.5902/1984644436043

\title{
Gestão democrática de alta intensidade: análise de uma experiência escolar em construção
}

\section{High intensity democratic management: analysis of a school experience under construction}

\section{Telmo Marcon}

Professor doutor na Universidade de Passo Fundo. Passo Fundo, Rio Grande do Sul, Brasil. telmomarcon@gmail.com - https://orcid.org/0000-0002-9110-3210

Consuelo Cristine Piaia

Professora doutora na Universidade Federal Fronteira Sul, campus Erechim. Erechim, Rio Grande do Sul, Brasil.

consuelo.piaia@uffs.edu.br - https://orcid.org/0000-0002-8406-7522

Recebido em 13 de dezembro de 2018

Aprovado em 09 de maio de 2019

Publicado em 13 de maio de 2020

\section{RESUMO}

O artigo de natureza bibliográfica e documental tem como objetivo analisar uma experiência de gestão democrática na escola pública estadual Zandoná em Barra Funda, Rio Grande do Sul. Essa escola vem construindo, desde 2001, uma gestão democrática de alta intensidade, envolvendo a comunidade escolar e organizações da sociedade civil, especialmente movimentos sociais. Boaventura de Sousa Santos, entre outros autores, vem chamando atenção para a necessidade de dar visibilidade às práticas democráticas em construção que conseguem superar compreensões de democracia como mero procedimento formal. Com base em produções bibliográficas sobre democracia e gestão democrática e em documentos e publicações da escola, serão analisadas algumas dimensões dessa experiência, os seus avanços e os desafios enfrentados. Para tanto, inicia-se com uma problematização mais geral do tema, segue-se com uma discussão sobre as potencialidades políticas e pedagógicas da gestão democrática e adentra-se a experiência da escola. As considerações finais reafirmam a tese de que essa experiência se constitui efetivamente numa democracia de alta intensidade e contém potencialidades para superar muitos dos problemas existentes na escola.

Palavras-chave: Democracia; Educação emancipadora; Gestão democrática escolar. 


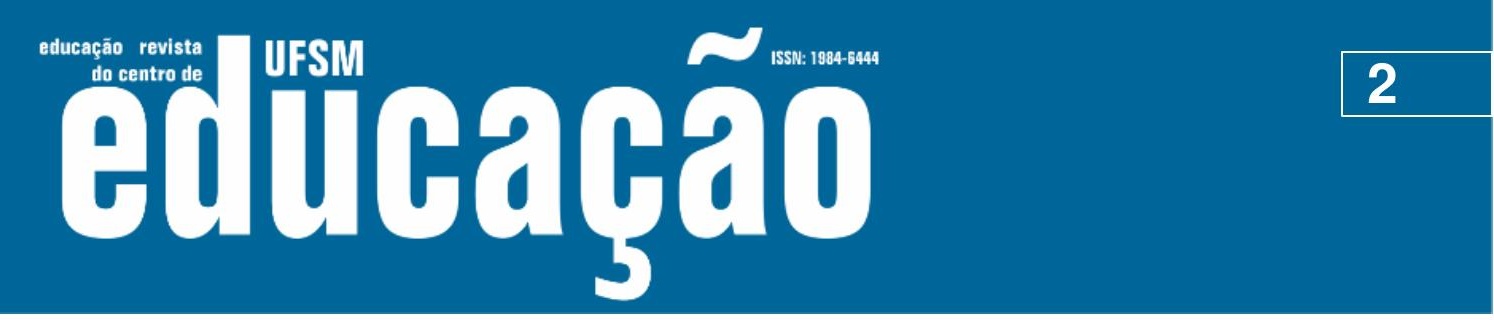

ISSN: 1984-6444 | http://dx.doi.org/10.5902/1984644436043

\section{ABSTRACT}

The paper of bibliographic and documental nature has the objective of analyzing an experience of democratic management in the public state school Zandoná in "Barra Funda", Rio Grande do Sul. This school has been building, since 2001, a high intensity democratic management, involving the school community and organizations of the civil society, especially social movements. Boaventura de Sousa Santos, among other authors, is calling attention for the need of giving visibility to democratic practices being built that are able to overcome comprehensions of democracy as merely a formal procedure. Based in productions of the bibliography about democracy and democratic management and in documents and publications from the schools, some dimensions of this experience, its advancements and challenges faced, will be analyzed. That starts with a more general problematization of the theme, followed by a discussion about political and pedagogic potentialities of the democratic management and enters the experience of the school. Final considerations reaffirm the thesis that this experience effectively constitutes a high intensity democracy and has potentialities to overcome many of the problems faced in the school.

Keywords: Democracy; Emancipating education; School democratic management.

\section{Introdução}

Os temas relativos à democracia e à gestão democrática da educação vêm ganhando espaço no âmbito das pesquisas em educação, ao mesmo tempo em que são muito questionados. Esse debate pode avançar muito mais com 0 aprofundamento de experiências positivas que vêm sendo construídas em diferentes espaços, particularmente, na escola, e precisam ganhar visibilidade. Experiências históricas vêm evidenciando o quanto é difícil dar conta da pluralidade de ideias, projetos e interesses pessoais e corporativos não apenas no âmbito da escola, mas das instituições sociais e da sociedade em geral.

A democracia compreendida como gestão pública (republicana) e como modos de vida, na perspectiva de Dewey (1979) e Benevides (1996), ganhou ao longo da história diferentes configurações. Elogiada por uns como a melhor forma de administrar conflitos e interesses, foi execrada por outros com base em argumentos diversos (CUNNINGHAM, 2009; RANCIÈRE, 2014). Busca-se, no presente texto, analisar a democracia como uma forma importante de gestar a coisa pública, mas também destacar a sua dimensão formativa de pessoas com espírito republicano e 


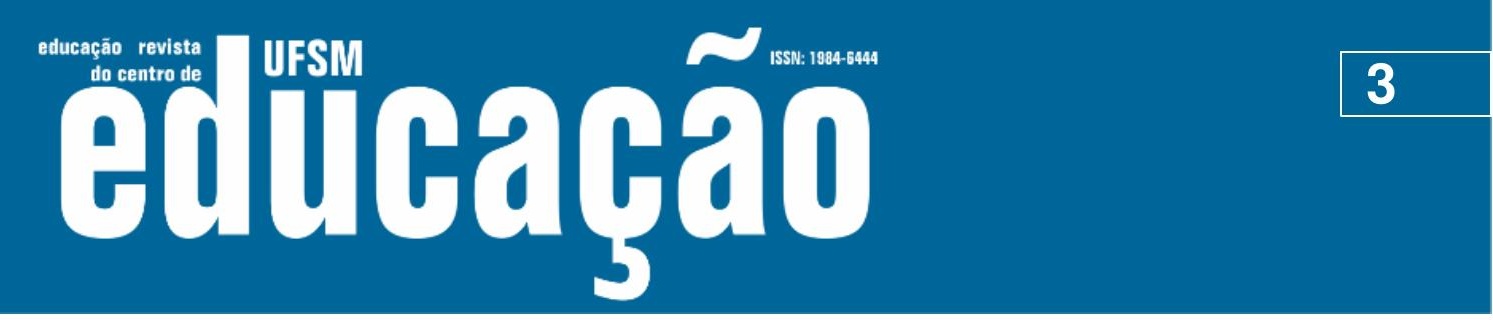

ISSN: 1984-6444 | http://dx.doi.org/10.5902/1984644436043

capacitadas para conviverem socialmente no contexto de sociedades complexas e plurais, na perspectiva apontada por Cenci e Marcon (2016, p. 111-130).

Buscando dar conta desses dois desafios, o texto inicia com uma problematização mais geral sobre a democracia e segue com a reconstrução da experiência que vem sendo desenvolvida na escola pública Zandoná, no município de Barra Funda, Rio Grande do Sul. Há quase duas décadas essa escola vem construindo uma experiência participativa e democrática significativa, superando várias dimensões das crises que se fazem presente na escola e nas demais instituições educativas. Que elementos sustentam a concretização dessa experiência? Quais os principais obstáculos enfrentados? Como a escola estabelece interlocuções com organizações da sociedade civil do município e da região e como dialoga com os pais e a comunidade em geral? Quais as práticas inovadoras que dão condições para essa escola constituir-se numa importante referência educativa democrática e cidadã?

\section{A democracia e suas implicações políticas e pedagógicas}

Vive-se um período histórico paradoxal: ao mesmo tempo em que se multiplicam as discussões sobre a democracia e ampliam-se as experiências de gestão democrática, proliferam discursos antidemocráticos, fundamentalistas e xenofóbicos. No âmbito dessas posturas excludentes, cresce a ideia de que é fundamental o direito de expressão, mas para negar a própria condição da democracia. Como afirma Casara (2017, p. 31), "Em nome da democracia, rompe-se com os princípios democráticos". Neste sentido, afirma-se o pressuposto da liberdade para negar a pluralidade e o direito de expressão de outros sujeitos.

De outro lado, discursos e práticas basistas esvaziam a democracia compreendida como formação política do cidadão, negando o seu sentido mais profundo de participação. Aqui, são identificados alguns limites da democracia tanto no sentido político (decisão e gestão), quanto na dimensão pedagógica (formação e pertencimento dos sujeitos). Como assinala Benincá existem diferenças substanciais 


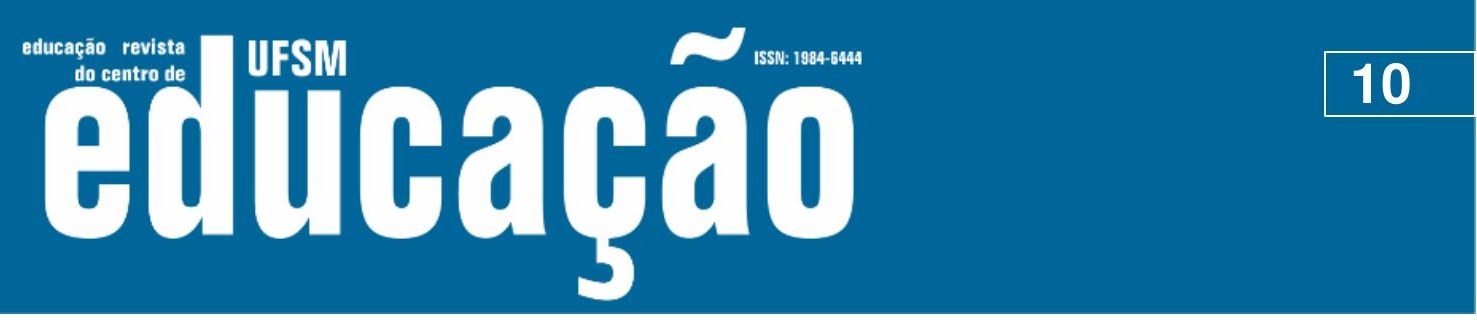

ISSN: 1984-6444 | http://dx.doi.org/10.5902/1984644436043

Os problemas existentes, a situação em que se encontram os verdadeiros interesses da população, o pensar que lhe parece mais significativo e preocupante, o resgate da identidade e o histórico dos que viveram e vivem no local, valorizando as experiências dos moradores, na tentativa de superar o definhamento dos que historicamente ainda estão marginalizados. O despertar pela vivência cidadã é uma das preocupações na realização da Pesquisa da Realidade (ESCOLA ZANDONÁ, 2013, p. 11).

Desse trabalho de pesquisa, emergem os Temas Geradores. Neste sentido, a escola não é um ente estranho no contexto, visto que atua em diálogo constante com a realidade local e o conhecimento produzido por pesquisas sobre a região é incorporado pelas diferentes disciplinas que são trabalhadas por áreas. Esse trabalho coletivo inclui o levantamento e sistematização de dados da realidade, as discussões durante as reuniões semanais de formação continuada, a elaboração do conteúdo a ser desenvolvido, a participação em eventos científicos na região e no país e tem contribuído para uma compreensão sociocultural e política mais ampla dos problemas locais e globais.

No âmbito desse contexto mais geral, a escola vem se destacando em várias dimensões, entre as quais no trabalho de iniciação científica, em processos inovadores de avaliação, nos conselhos de classe participativos, na preparação conjunta das aulas e dos conteúdos a serem desenvolvidos pelos professores, nas atividades esportivas e culturais, especialmente no evento anual denominado Caldeirão da Juventude, na música e no teatro, através de um diálogo intenso com lideranças de movimentos e organizações sociais. Tudo isso vem sendo realizado com muito empenho, mas também tem produzindo muitas tensões que são inerentes aos processos participativos e democráticos. Em meio aos embates, estão emergindo práticas inovadoras e significativas, especialmente no atual contexto de crise da escola. O papel das humanidades ganha, nesse contexto, um destaque especial.

A experiência da escola Zandoná permite colocar em pauta um conjunto de questões e possibilidades. Procurando dar conta de algumas delas, serão, aqui, priorizadas: a) a pesquisa na constituição dos temas geradores; b) a função acadêmica e formativa da iniciação científica; c) a avaliação como instrumento de participação e qualificação pedagógica. 


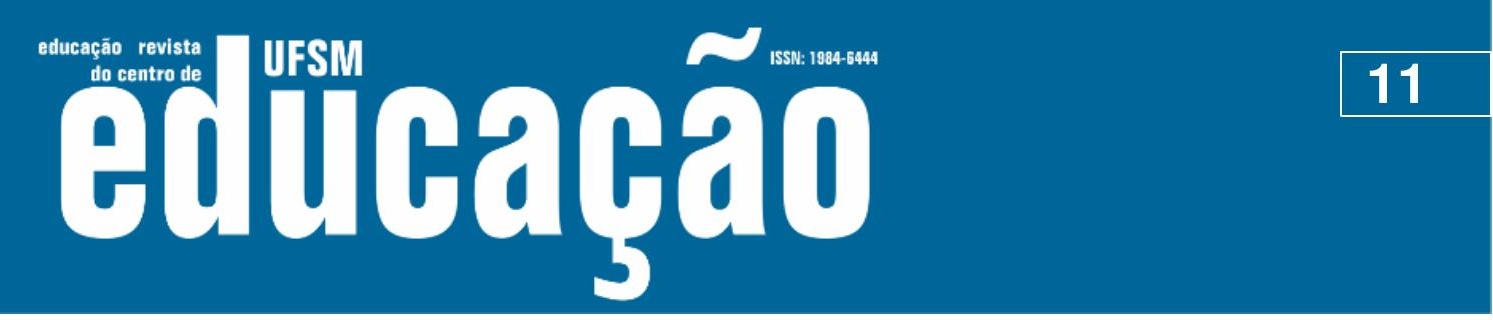

ISSN: 1984-6444 | http://dx.doi.org/10.5902/1984644436043

\section{a) Organização pedagógica: a opção pela pesquisa participante e a constituição dos temas geradores}

A pesquisa do contexto escolar ocorre com a participação de alunos, funcionários e professores na perspectiva de um trabalho pedagógico interdisciplinar. $\mathrm{Na}$ configuração de novos jeitos de atuar, a referida instituição foi construindo uma experiência de gestão democrática que vem se tornando uma referência importante para a construção de uma proposta coletiva de educação. Como a escola consegue estabelecer interlocuções com as organizações da sociedade civil, com os pais, os gestores, os alunos e os professores?

Durante muitos anos, a Escola Zandoná desenvolveu um trabalho pedagógico em nada diferenciado às demais escolas. As mudanças na instituição iniciaram no ano 2000 no contexto da Constituinte Escolar, que foi desencadeada pelo governo estadual de Olívio Dutra (1999-2002) e tinha como objetivo, segundo Fleuri (2001, p. 116):

Promover a construção da democracia participativa. Junto com outros instrumentos, como o orçamento participativo, pretende promover a participação popular na definição e no controle de políticas públicas. 0 movimento é conduzido pela Secretaria de Educação, que abre espaços para a participação das comunidades escolares (educadores, pais, estudantes e funcionários), de movimentos sociais populares, de instituições de ensino superior e instituições do poder público.

A Constituinte Escolar não tinha apenas o objetivo de mobilizar a comunidade em relação à educação escolar, mas propunha uma nova concepção de conhecimento a ser produzida numa interação dialética entre a escola e a comunidade. Piaia (2016, p. 97) sintetiza a concepção central da Constituinte Escolar afirmando que, como política pública:

\footnotetext{
Instituiu-se como uma opção de reorganização escolar a partir de leituras e encontros que incentivavam a participação da comunidade nessa tarefa. Essa política educacional baseou-se em uma opção pela Concepção Dialética de Conhecimento e pela metodologia de Pesquisa Participante e diferenciou-se de outras experiências por privilegiar o trabalho com os grupos sociais historicamente alijados dos processos econômicos, sociais, culturais.
}

Ao construir o Plano Pedagógico com a comunidade escolar, a instituição optou por desenvolver uma educação inspirada teoricamente na pedagogia freireana, visando à emancipação dos oprimidos. A preocupação com os sujeitos que lutam pela 


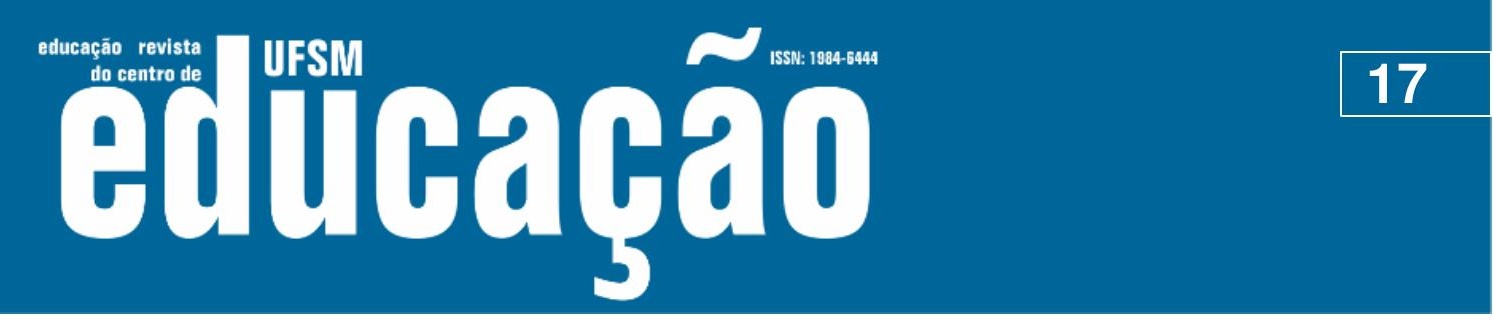

ISSN: 1984-6444 | http://dx.doi.org/10.5902/1984644436043

objeto de estudo. A culminância da pesquisa ocorre com a apresentação dos resultados em feiras de ciência, mas também em atividades internas na escola. A feira de ciências é, na escola, um desses momentos e ocorre anualmente, em geral, no final do primeiro semestre quando se dá o encerramento dos projetos de iniciação científica que começam a ser desenvolvidos no início de cada ano letivo. Esse evento tem uma abertura que é marcante para a escola porque trabalha uma temática eleita pelo coletivo da própria escola. Uma equipe prepara uma peça teatral baseada na temática escolhida. A respeito dessa atividade, a professora da escola Ivete Terezinha Zandoná faz a seguinte descrição:

\begin{abstract}
A organização e a montagem do espetáculo é tarefa que exige muita criatividade e dedicação das educadoras responsáveis pela apresentação. Várias atividades precisam ser desenvolvidas para realizá-la, tais como: leitura da realidade socioeconômica-cultural, estudo, análise e compreensão do tema, concepção do espetáculo, reflexão da prática, elaboração dos personagens, concepção e confecção dos figurinos e cenários, criação da trilha sonora, preparação dos atores nas mais diversas atividades como: interpretação, canto, dança e habilidades corporais. (ZANDONÁ, 2013, p. 110).
\end{abstract}

A título de ilustração, pode-se destacar os temas e os objetivos que nortearam três edições: em 2006, foi representada a "Parábola das Mãos Amarradas", tendo, como objetivo, "remeter à ideia de que a educação exige saber escutar e não ficar parado, atrofiando a capacidade de pensar, falar e agir". Em 2009, o tema inspirador foi "Alice no País das Maravilhas", com o objetivo de "representar a Teoria da Evolução de Darwin e a literatura musical de We are the world (Nós somos o mundo)". Em 2012, o tema foi a "defesa dos direitos humanos", com o objetivo de "ajudar a construir a consciência que a defesa dos direitos humanos foi e continua sendo uma tarefa de indivíduos dentro de uma coletividade que se recusam a ficar calados, que se descobrem humanos e buscam lutar contra todas as formas que desumanizam". 0 quadro completo com as edições anuais, incluindo os temas e os respectivos objetivos, desde 2006 até 2014, pode ser encontrado em Piaia (2016, p. 107).

\title{
c) A avaliação como instrumento de participação e qualificação pedagógica
}

Na Escola Zandoná, a avaliação é parte constitutiva do processo pedagógico. Os pareceres sobre as atividades propostas resultam da participação ativa do coletivo 


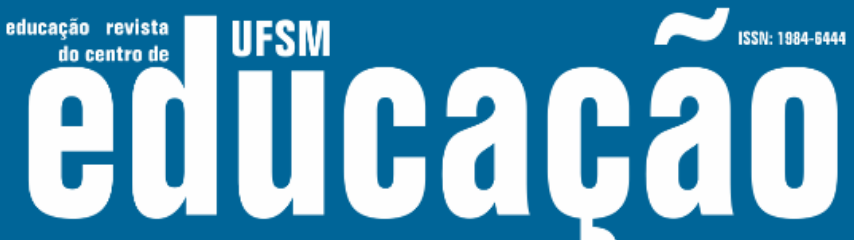

ISSN: 1984-6444 | http://dx.doi.org/10.5902/1984644436043

evitam-se críticas individuais, ataques ou acusações. Há um cuidado com a fala de alunos, professores e pais no sentido de não ofenderem ninguém e nem criar um ambiente de intolerância. $O$ princípio básico que orienta 0 trabalho tem uma perspectiva emancipadora e democrática, que questiona relações educativas autoritárias, muito presentes nas relações sociais, bem como dentro escola. $\mathrm{O}$ processo avaliativo constitui-se num momento de diálogo e, por isso, é assumido pelo coletivo.

As discussões e as decisões tomadas durante a avaliação são retomadas no próximo Conselho de Classe Participativo. O que se observa é que, mesmo com os avanços na participação dos sujeitos e na construção de um ambiente propício ao diálogo, nem tudo ocorre da forma desejada. A aproximação com sindicatos, pastorais, movimentos sociais populares e a efetivação da proposta pedagógica emancipadora na Escola Zandoná não foram e não são unanimidade. Disputas, contradições, concepções e interesses distintos, quando não antagônicos, produzem embates que afloram em processos democráticos e participativos. Há segmentos dentro da escola e também da comunidade que defendem metodologias bancárias e não emancipadoras, conforme propõe Freire em Pedagogia do oprimido (1987). Há momentos em que afloram mágoas e desconfianças. Nessas circunstâncias, tem sido fundamental o papel dos coordenadores na retomada dos princípios democráticos da gestão e dos pressupostos emancipadores da educação.

Esses elementos permitem concluir que a Escola Zandoná vem construindo uma experiência histórica que contém inúmeras práticas que dão significados peculiares aos sujeitos envolvidos. Enquanto experiência, ela carrega a potencialidade de ser um processo educativo emancipador. Apesar de a escola estar situada num contexto histórico e social permeado por conflitos, interesses e contradições, abrem-se possibilidades importantes de ação humana no sentido de constituição dos indivíduos, conforme Elias (1994, p. 13-60) e Charlot (2000). 


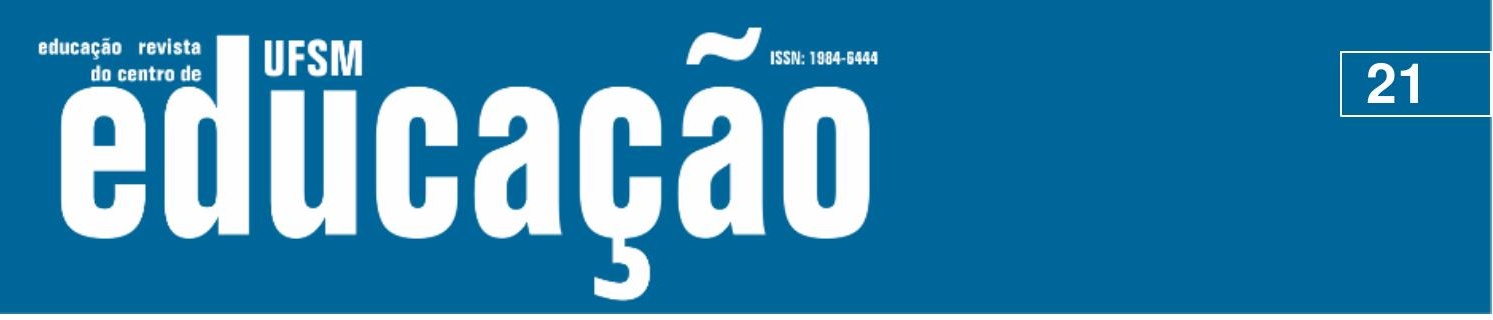

ISSN: 1984-6444 | http://dx.doi.org/10.5902/1984644436043

\section{Considerações finais}

A reconstrução da experiência educativa desenvolvida na escola Zandoná destacou apenas alguns aspectos de um conjunto de dimensões presentes no fazer pedagógico. Mesmo encontrando dificuldades internas e externas, a comunidade escolar vem realizando um jeito novo de educar que está conseguindo ressignificar a escola compreendida como instituição educativa. Como afirmaria Charlot, "as questões de atividade intelectual, do sentido, do prazer, na minha opinião, são chaves do ensino" (2002, p. 18). A escola vem desenvolvendo uma proposta pedagógica que consegue fazer com que os alunos se mobilizem. O que vem caracterizando essa experiência como inovadora é a capacidade e o empenho em debruçar-se sobre o contexto onde ela está situada, especialmente através de pesquisa de campo que resulta na constituição dos temas geradores. São esses temas que dinamizam um trabalho diferenciado no âmbito das disciplinas que não são trabalhadas isoladamente, mas por áreas de conhecimento.

Uma segunda dimensão importante nesse novo jeito de ser da escola diz respeito à participação democrática da comunidade escolar em todos os momentos, incluindo a pesquisa de campo, a seleção de falas expressivas do conhecimento espontâneo, a construção do conteúdo a ser desenvolvido, a preparação conjunta das aulas e a avaliação permanente das atividades realizadas. Em distintos momentos, alunos, funcionários, professores e a comunidade externa à escola vivenciam experiências educativas e culturais que são decisivas na formação democrática do cidadão e na construção da própria democracia. Fortalece-se, assim, o pressuposto que a democracia de alta intensidade, conforme preconizam Santos e Avritzer (2009, p. 38-82), somente é possível com uma formação democrática permanente (DEWEY, 1979; BENEVIDES, 1996, p. 223-237).

$\mathrm{Na}$ contramão de discursos que tendem a esvaziar a dimensão política da escola, a experiência da Escola Zandoná reforça a importância de a instituição escolar assumir que a sua prática é política. $O$ ato educativo é compreendido como prática política na medida em que contribui para a formação do cidadão em todas as dimensões, não apenas para o trabalho. É evidente que esse posicionamento não é 


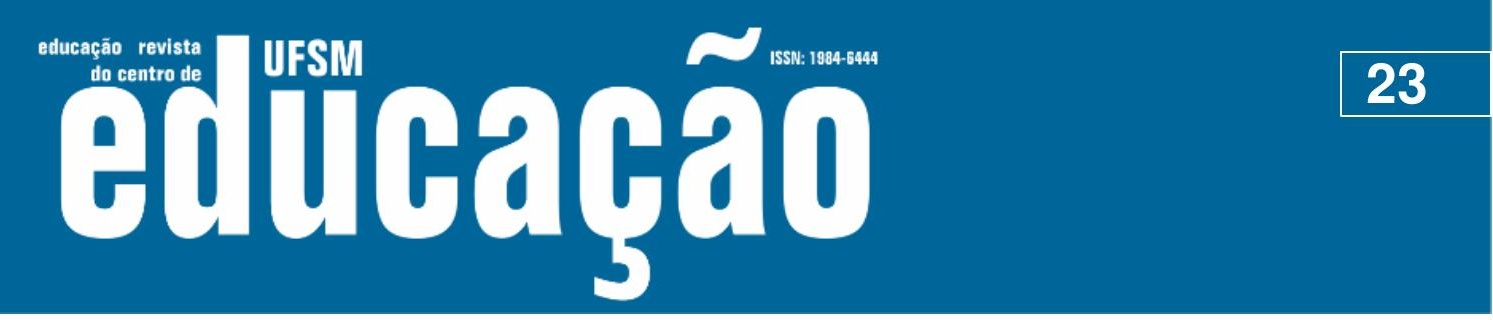

ISSN: 1984-6444 | http://dx.doi.org/10.5902/1984644436043

BENEVIDES, Maria Vitória. Educação para a democracia. Lua Nova, São Paulo, n. 38, p. 223-237, 1996.

BENINCÁ, Elli. A prática pedagógica na sala de aula: princípios e métodos de uma ação dialógica. In: MÜHL, Eldon Henrique (org.). Educação, práxis e ressignificação pedagógica. Passo Fundo: UPF Editora, 2010, p. 109-124.

BOFF, Leonardo. Fundamentalismo: a globalização e o futuro da humanidade. Rio de Janeiro: Sextante, 2002.

CARINI, Joel João. Estado, índios e colonos: o conflito na reserva indígena de Serrinha, norte do Rio Grande do Sul. 2005. Dissertação (Mestrado em História) Instituto de Filosofia e Ciências Humanas, Universidade de Passo Fundo, Passo Fundo, 2005.

CASARA, Rubens Roberto Rebello. Estado pós-democrático: neo-obscurantismo e gestão dos indesejáveis. Rio de Janeiro: Guanabara, 2017.

CENCI, Ângelo Vitório; MARCON, Telmo. Sociedades complexas e desafios educativos: individualização, socialização e democracia. In: MÜHL, Eldon Henrique; DALBOSCO, Cláudio Almir; CENCI, Ângelo Vitório (Orgs.). Questões atuais de educação: sociedade complexa, pensamento pós-metafísico, democracia e formação humana. Ijuí: EdUnijui, 2016, p. 111-130.

CHARLOT, Bernard. Mistificação pedagógica. Rio de Janeiro: Zahar, 1979.

CHARLOT, Bernard. Da relação com o saber. Porto Alegre: Artmed, 2000.

CHARLOT, Bernard. Relação com a escola e o saber nos bairros populares. Revista Perspectiva, Florianópolis, v. 20, p. 17-34, jul./dez, 2002.

CHAUÍ, Marilena. Cultura e democracia: o discurso competente e outras falas. 12.ed. São Paulo: Cortez, 2007

CUNNINGHAM, Frank. Teorias da democracia: uma introdução crítica. Porto Alegre: Artmed, 2009.

DAMATTA, Roberto. Carnavais, malandros e heróis. Rio de Janeiro: Zahar, 1981.

DEWEY, John. Democracia e Educação: introdução à filosofia da educação. 4. ed. São Paulo: Editora Nacional, 1979.

ELIAS, Norbert. A sociedade dos indivíduos. Rio de Janeiro: Zahar, 1994.

ESCOLA ZANDONÁ. Proposta Político-Pedagógica. Barra Funda, 2013 (mimeo).

FAORO, Raymundo. Os donos do poder: formação do patronato brasileiro. 6.ed. Rio de Janeiro: Globo, 1984, v. I. 


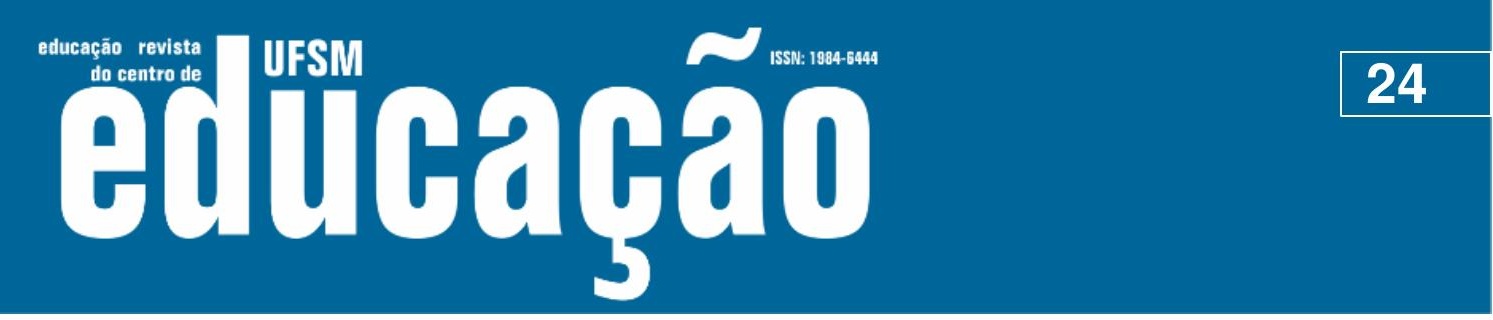

ISSN: 1984-6444 | http://dx.doi.org/10.5902/1984644436043

FAORO, Raymundo. Os donos do poder: formação do patronato brasileiro. 8.ed. Rio de Janeiro: Globo, 1989, v. II.

FERNANDES, Florestan. Integração do negro na sociedade de classes. 3.ed. São Paulo: Ática, 1978 (v. I).

FERNANDES, Florestan. A sociologia no Brasil: contribuição para o estudo de sua formação e desenvolvimento. 2.ed. Petrópolis: Vozes, 1980.

FLEURI, Reinaldo. Entre o oficial e o alternativo em propostas curriculares: para além do hibridismo. Revista Brasileira de Educação, Rio de Janeiro, n. 17, p. 115-154, Maio/Ago, 2001.

FREIRE, Paulo. Pedagogia do oprimido. 3.ed. Rio de Janeiro: Paz e Terra, 1987.

FREYRE, Gilberto. Casa Grande e Senzala. 25.ed. Rio de Janeiro: José Olympio, 1987.

GHELEN, Ivaldo. Uma estratégia camponesa de conquista da terra e o Estado: o caso da Fazenda Sarandi. 1983. Dissertação (Mestrado em Sociologia) Universidade Federal do Rio Grande do Sul, Porto Alegre, 1983.

HOLANDA, Sério Buarque de. Raízes do Brasil. 27.ed. São Paulo: Companhia das Letras, 2014.

LAROSSA, Jorge. Tremores: escritos sobre experiência. Belo Horizonte: Autêntica, 2017.

MARCON, Telmo. Os movimentos sociais como educadores: contribuições políticas e pedagógicas do Acampamento Natalino. Passo Fundo: UPF Editora, 2016.

NUSSBAUM, Martha. El cultivo de la humanidade: em defensa clássica de la reforma en la educación liberal. Barcelona: Paidós, 2005.

NUSSBAUM, Martha. Sin fines de lucro: por qué la democracia necessita de las humanidades. Buenos Aires: Katz Editores, 2010.

PIAIA, Cristine Consuelo. Desafios e possibilidades do diálogo entre escola e movimentos sociais: estudo de caso em uma escola pública, 2008. Dissertação (Mestrado em Educação) - Universidade de Passo Fundo, Passo Fundo, 2008.

PIAIA, Consuelo Cristine. A crise da escola e as possibilidades de sua ressignificação sociopolítica e cultural. Tese (Doutorado em Educação) Faculdade de Educação, Universidade de Passo Fundo, Passo Fundo, 2016.

PLATÃO. La República. Madrid: Edimat Libros, 2000.

RANCIÈRE, Jacques. O ódio à democracia. Belo Horizonte: Boitempo, 2014. 


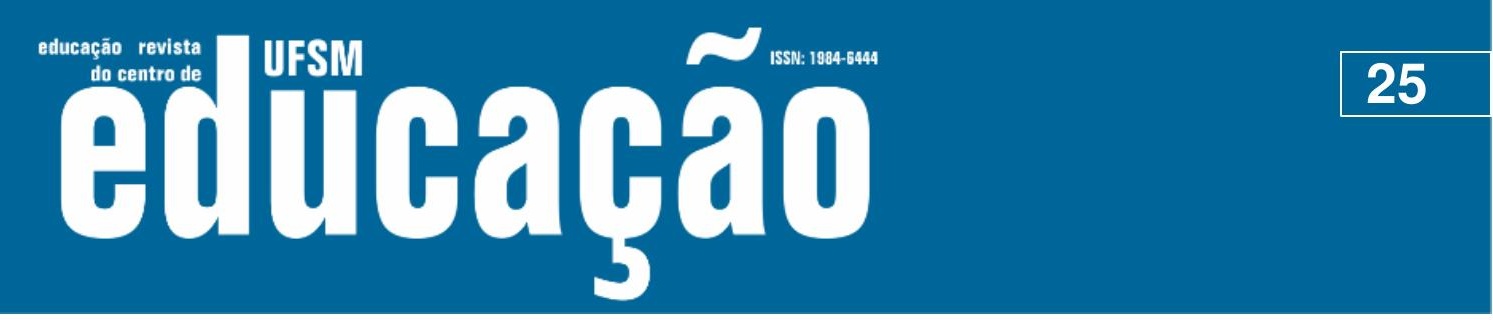

ISSN: 1984-6444 | http://dx.doi.org/10.5902/1984644436043

ROSSETTO, Cândida. Educadores e educandos: autoria na feira de Iniciação à pesquisa. In: ROSSETTO, Cândida; PIAIA, Karine. (Org.). Construir-se: um ato de ousadia e esperança 60 Anos da Escola Zandoná. Passo Fundo: Salus, 2013.

SANTOS, Boaventura de Sousa; AVRITZER, Leonardo. Introdução: para ampliar o cânone democrático. In: SANTOS, Boaventura de Sousa (Org.). Democratizar a democracia: os caminhos da democracia participativa. Rio de Janeiro: Civilização Brasileira, 2009, p. 38-82.

SANTOS, Boaventura de Souza. A crise do contrato social da modernidade e a emergência do fascismo social. In: SANTOS, Boaventura de Souza. Gramático do tempo: para uma nova cultura política. 2.ed. São Paulo: Cortez, 2008, p. 317-340.

SIGNOR, Patrícia; PIAIA, Karine. Conselho de classe: momento de reflexão sobre o fazer pedagógico na Escola Estadual Zandoná. Jornal A Região, Sarandi: 12.6.2013, p 6.

SILVA, Juremir Machado da. Raízes do conservadorismo brasileiro: abolição na imprensa e no imaginário social. Rio de Janeiro: Civilização brasileira, 2017.

SOUZA, Jessé. A ralé brasileira: que é e como vive. Belo Horizonte: EdUFMG, 2009.

SOUZA, Jessé. Os batalhadores brasileiros: nova classe média ou nova classe trabalhadora? Belo Horizonte: EdUFMG, 2012.

SOUZA, Jessé. A tolice da inteligência brasileira: ou como o país se deixa manipular pela elite. São Paulo: LeYa, 2015.

TEDESCO, João Carlos. O conflito de Nonoai: um marco na história das lutas pela terra no Rio Grande do Sul - 1978-1982. Sæculum - Revista de História, João Pessoa, n. 26, p. 241-259, jan./jun. 2012.

TEDESCO, João Carlos; MARCON, Telmo. As transformações na agricultura e as terras indígenas. In: MARCON, Telmo (Org.). História e cultura Kaingang no sul do Brasil. Passo Fundo: UPF Editora, 1994. p. 163-199.

ZANDONÁ. Ivete Terezinha. A arte dialogando com a ciência na abertura das Feiras de Iniciação à Pesquisa. In: ROSSETTO, Cândida.; PIAIA, Karine. (Org.). Construirse: um ato de ousadia e esperança 60 Anos da Escola Zandoná. Passo Fundo: Salus, 2013, p. 110-115.

\section{Correspondência}

Telmo Marcon - Universidade de Passo Fundo - Campus I, São José, CEP 99001 970, Passo Fundo, Rio Grande do Sul, Brasil. 


\section{Wusm

ISSN: 1984-6444 | http://dx.doi.org/10.5902/1984644436043

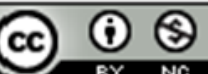

\section{This work is licensed under a Creative Commons Attribution-NonCommercial 4.0 International (CC BY-NC 4.0)}

\section{Notas}

1 É importante observar que, no contexto de Platão e Aristóteles, a participação democrática era limitada a homens (masculino) livres. Essa delimitação excluía escravos, mulheres e as gerações não adultas. Mesmo assim, a participação de todos os homens livres constituía-se num problema.

2 Para Charlot, a escola torna-se ideológica quando reforça a dicotomia e um distanciamento em relação à sociedade, sendo que a primeira fecha-se em relação a segunda.

3 O portfólio consiste numa pasta com material individual do aluno e é tratado como documento avaliativo pela escola. Ele contempla um índice do material seguido dos dados de identificação do aluno e da área de conhecimento. As páginas são enumeradas e contêm atividades, autoavaliação, textos e fichamentos, ou seja, os trabalhos dos alunos e as anotações das docentes responsáveis pela área de conhecimento junto aos trabalhos avaliativos. É um instrumento importante que permite avaliar o processo de ensino e aprendizagem do aluno. No mesmo documento, constam os critérios de avaliação em cada atividade realizada e permite que o aluno, o professor e a comunidade escolar saibam quais serão os critérios pelos quais os educandos serão avaliados. 